\title{
Modeling of the microstructure alteration induced by hard turning of Inconel 718
}

Heithem Touazine ${ }^{1} \cdot$ Jordan Akab $^{2} \cdot$ Mohammad Jahazi $^{1} \cdot$ Antoine Tahan $^{1}$. Walid Jomaa $^{3} \cdot$ Philippe Bocher $^{1}$

Received: 21 December 2016/Accepted: 7 July 2017

(C) Springer-Verlag London Ltd. 2017

Authors' accepted manuscript, article published in

The International Journal of Advanced Manufacturing Technology, vol. 93 issue 9-12, p. 3705-3712 (2017) https://doi.org/10.1007/s00170-017-0787-y

The final publication is available at link.springer.com 


\title{
Modeling of the microstructure alteration induced by hard turning of Inconel 718
}

\author{
Heithem Touazine $^{\mathrm{a} *}$, Jordan Akab ${ }^{\mathrm{b}}$, Mohammad Jahazi ${ }^{\mathrm{a}}$, Antoine Tahan ${ }^{\mathrm{a}}$, Walid \\ Jomaa $^{\mathrm{c}}$, Philippe Bocher ${ }^{\mathrm{a}}$
}

\author{
${ }^{a}$ École de technologie supérieure, 1100 Notre-Dame Street West H3C1K3, Montreal, Canada \\ ${ }^{b}$ École nationale supérieure de mécanique et d'aérotechnique de Poitiers \\ ${ }^{c}$ Laval university, Quebec (QC), Canada
}
* Corresponding author. Tel.:+1 514-926-8701; E-mail address:
heithem.touazine@gmail.com

\begin{abstract}
The machining of nickel-based superalloys used for aeronautical applications generates damage, deformation and carbide cracking in machined surface and subsurface layers as a result of microstructural heterogeneities which reduce the fatigue life of aeronautic machined components. In this study, Inconel 718 was hard turned with a carbide tool using different cutting conditions according to a Roquemore 311B hybrid design of experiments (DOE) method. The main objective of the study was to model the effect of cutting parameters on the evolution of the microstructure and to accurately predict the alterations induced by machining, especially the deformed layer thickness $(D L)$ and the average number of cracked carbides $(A C C)$. The material removal rate $(M R R)$ and the deformation power $(E)$ were calculated in order to obtain a strong correlation between controlled cutting parameters and microstructure alterations. Damages were quantified using a confocal laser-digital microscope and were validated with the proposed models. These models showed a direct relation between both and $E$ with $D L$ and $A C C$, with good prediction at a $95 \%$ confidence interval $(C I)$.
\end{abstract}

\section{Keywords}

Hard turning; modeling; microstructure alteration; deformed layer; cracked carbides. 


\section{Nomenclature}

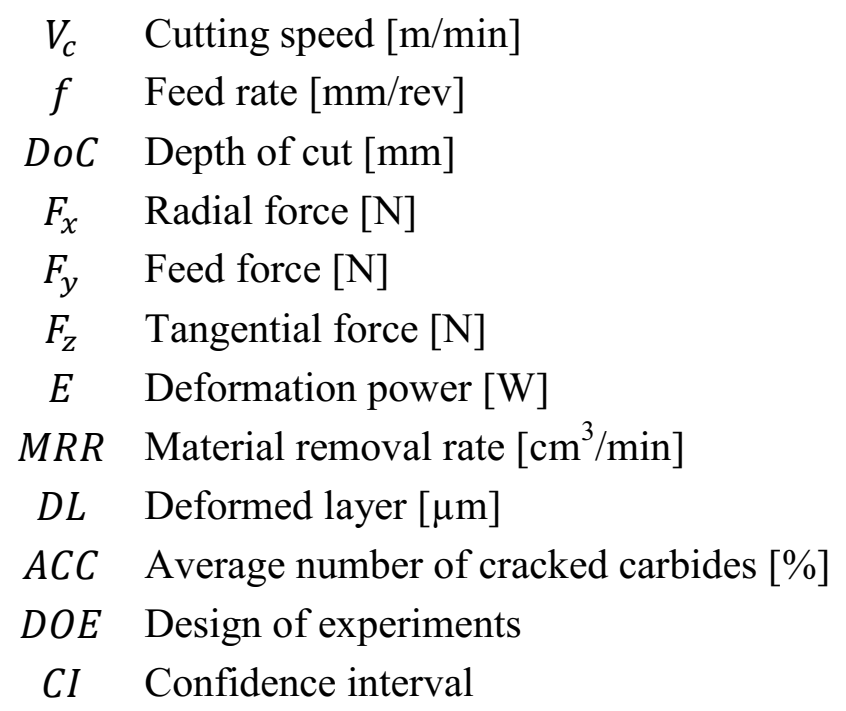

\section{Introduction}

Nickel-based superalloys, such as Inconel 718, are widely used in the aerospace industry because of their great mechanical properties, including creep [1], oxidation [2], corrosion resistance [3], as well as high temperature workability [4]. Inconel 718 is commonly used in aircraft engines and gas turbine hot sections [5-7], and accounts for approximately $75 \%$ of the composition of modern jet engines [8]. Nevertheless, some microstructural characteristics such as work hardening [9] and carbide particles [10] make it difficult to machine; additionally, the materials generate surface integrity alterations and discontinuities. In our previous study, we reported on microstructural alterations induced by the hard turning of Inconel 718 in subsurface layers, including a deformed layer, cracked niobium carbides, and higher hardness due to work hardening [11, 12]. According to Zhou et al. [10], the cracking of niobium carbides results from the pressure applied by the tool on the machined surface. In their investigations, Kitagawa et al. [13] and Zhou et al. [14] reported that machining conditions, especially tool wear during machining, could induce recrystallization and severe plastic deformation in the subsurface layers, resulting in the degradation of the machined part quality.

Discontinuities and defects generated in the subsurface layers during the machining of Inconel 718 can have a significant impact on the fatigue life of machined components [15, 16]. The formation of these discontinuities depends on cutting parameters, such as the cutting speed, the depth of cut, and the feed rate. Coelho et al. [17] investigated the effect of work hardening on the machined subsurface by considering the evolution of microhardness. They 
observed that the surface hardness values obtained were slightly higher for lower cutting speeds. Reporting on the deformed layer, Sharman et al. [18] found that the thickness of deformation increased with an increasing feed rate and cutting speed.

The literature contains several publications on experimental modeling and predictions of roughness [19-23] and residual stresses [24-26] generated during the machining of nickelbased superalloys under different cutting conditions. However, that is far from the case when it comes to the experimental modeling of microstructural alterations. There is a need for an accurate experimental model to predict the evolution of the thickness of the $D L$ and $A C C$ based on cutting conditions.

In the above context, the present authors reported on an experimental method that accurately quantifies the thickness of the damaged layer generated during hard turning operation [11]. The present study focuses on the development of statistical models describing the evolution of the $(D L)$ and $(A C C)$, based solely on experimental data obtained using a response surface methodology $(R S M)$. The validity and accuracy of the proposed models are verified by two additional cutting conditions, namely, the cutting speed $\left(V_{c}\right)$, the depth of cut $(D o C)$, and the feed rate $(f)$, in the valid numerical range established in the $(D O E)$.

\section{Experiments and characterization}

\subsection{Materials and methods}

Hard turning tests were carried out using a MAZAK-NEXUS CNC center and carbide tools on a $50 \mathrm{~mm}$ diameter workpiece of investigated nickel-base superalloy. The chemical composition of the investigated alloy is presented in Table 1. Machined specimens were then heat treated as per AMS 5663, and an average grain size of $20 \mu \mathrm{m}$ was measured according to ASTM E112-13. $30 \mathrm{~mm}$ by $20 \mathrm{~mm}$ samples were cut from these specimens by wire electrical discharge machining (W-EDM) using an AGIECHARMILLES CUT $30 \mathrm{P}$ machine to minimize distortion during cutting. Sectioning was performed in two directions: transversal (perpendicular to the feed direction) and longitudinal (parallel to the feed direction of the tool), as shown in Fig.1.

Deformed grains at the sample surface and subsurface were revealed using a chemical etchant solution with a $1 / 3 \mathrm{H}_{2} \mathrm{O}_{2}(30 \%)$ and $2 / 3 \mathrm{HCl}$ composition [11]. The quantification of the microstructure alterations, i.e., in terms of the deformed layer thickness and average of cracked carbides $A C C$, was conducted using an OLYMPUS LEXT OLS 4100 laser-confocal microscope. 


\subsection{Design of experiment}

In order to study the effect of cutting parameters on the microstructural alterations, the experimental study was conducted using the hybrid design of experiments which was developed by Roquemore 311B (1976) [27]. For three factors, this design is effective in terms of the number of runs and with few experimental tests still have the same characteristics as central composite designs. Rosadelima and Lou [28] found that Roquemore 311B is the most suitable design for three input factors since it had the most stable prediction variance, which had also the lowest dispersion. Similarly, Fang et al. [29] showed that 311B is the best DOE performer in terms of scaled prediction variance performance for second order response.

In this study, the designed plan included three (3) factors and eleven (11) runs. The stability and the repeatability of the set-up were verified using three (3) replications of the center design. The control factors selected were: the cutting speed $V_{c}[\mathrm{~m} / \mathrm{min}]$, the feed rate $f$ $[\mathrm{mm} / \mathrm{rev}]$, and the depth of cut $D o C[\mathrm{~mm}]$. In order to eliminate the effect of tool wear, a new carbide tool was used for each run. Table 2 shows the different levels of cutting parameters tested.

As recommended by the Roquemore 311B, eleven (11) tests were performed in this experimental study. Also, the stability and the repeatability of the set-up were verified using two (2) replications of the center design, as shown by the runs 8 and 13 in Table 3.

For each run, tangential cutting force $\left(F_{Z}\right)$ was measured using a 9121 KISTLER dynamometer table. In addition the depth of the deformed layer and the average of cracked carbides were quantified and reported in the Table 3. Figs. 2 and 3 show a typical example of the cracked carbides and deformations observed in the subsurface after machining.

In order to generate statistical models and graphs representing the evolutions of the $D L$ and average $A C C$ at a $C I$ of $95 \%$, statistical software STATGRAPHICS centurion XVI was used.

\section{Results and discussion}

A typical machined subsurface is shown in Fig. 2, where the presence of both cracked and non-cracked carbides is observed. The ACC was calculated by counting all carbides located within $30 \mu \mathrm{m}$ of the machined surface. Fig. 3 shows deformed grain boundaries near the machined surface of a typical specimen. The limit of the deformed grain boundaries are highlight by a Yellow line based on visual inspection using optical microscopy. The thickness of $D L$ was measured from the machined surface to the deepest distorted grain boundary, as described by Touazine et al. [11]. All calculated values are reported in Table 3. 
The experimental results were analyzed in order to evaluate the impact of cutting parameters on microstructural alterations. Pareto diagrams were represented by Fig.4 and Fig.5. The vertical blue line corresponds to the threshold value beyond which factors become statistically significant at $95 \%$ confidence interval. In the case of three factor and $95 \%$ of confidence interval, the threshold value equal to 2.353. Fig.4 and Fig.5, show that the feed has the greatest effect on $A C C$ and $D L$ compared to $V C$ and $D o C$. The higher amount of plastic deformation generated with increasing the feed rate can explain these tendencies. In fact, greater strain accumulation is produced which may cause the cracking of the carbide particles. The results are in good agreement with those published by Liu et al [30] and by Pawade et al. [31]. Also, Sadat and Bailey concluded that the intensity of the surface damage increases with increasing feed rate [32].

In the present experimental study, the classic $R S M$ technique was not considered for the determination of a statistical correlation between cutting parameters $(V c, f$ and $D o C)$ and microstructural damages $(A C C$ and $D L)$. Instead, for further analysis and in order to properly evaluate the effect of the cutting parameters on $D L$ and $A C C, M R R\left[\mathrm{~cm}^{3} / \mathrm{min}\right]$ and estimated deformation power $E[\mathrm{~W}]$ were calculated using equations (1) and (2).

$$
\begin{gathered}
M R R=V_{c} \cdot f \cdot D o C \\
E=F_{z} \cdot V_{c}
\end{gathered}
$$

The use of $E$ and $M R R$ as separate inputs for the predictive models presents three main advantages: 1) more degrees of freedom will be added and universal correlation can be easily drawn; 2) Reduce the number of factors and the interactions between the three (3) cutting parameters, which can be generated with a different combination of $V c, f$ and $D o C$; 3) Avoid the nonlinear behavior of the responses using polynomial statistical correlation with RSM technique and simplify the equation by eliminating interactions between cutting parameters.

\subsection{Modeling of the deformed layer thickness evolution}

During machining, the deformed layer evolves with different cutting parameters [33]. This evolution can influence the hardness, thickness, and type of defects generated on the affected surface after final machining [11,34]. Only few studies have examined the relationship between microstructural alterations and cutting parameters [35, 36].

A statistical regression analysis of the results was carried out in order to establish a correlation between $E, M R R$, and $D L$. Fig. 6 shows that an increase in $M R R$ generates a proportional increase in $E$. As showed by equation $1, M R R$ increases as a function of 
increasing cutting speed, feed rate, and depth of cut, which consequently, increases the amount of power required for material removal. For the cutting conditions examined here (see Table 3), the calculated $M R R$ is between 0.2 and $4.6 \mathrm{~cm}^{3} / \mathrm{min}$ and $E$ between 45 and $338 \mathrm{~W}$.

An analysis of variance (ANOVA) was carried out to describe the correlation between the output $(D L)$ and inputs $(M M R$ and $E)$. Table 4 provides a summary of the statistics obtained for the best fit curves. This analysis reveals that the evolution of the $D L$ is best described by a square root function. The adjusted coefficients of correlation $R_{a d j}^{2}$ are 97.5 and $89.3 \%$ and $P$ value is 0 for both configurations, indicated a strong correlation between the inputs and output of the model.

Figs. 7 and 8 show an increase in $D L$ thickness with increasing $E$ and $M R R$. Specifically, thickness values varying between 6 and $15.5 \mu \mathrm{m}$ were measured for $M R R$ values ranging between 0.2 to $3.9 \mathrm{~cm}^{3} / \mathrm{min}$ and $E$ values between 45 to $245 \mathrm{~W}$. This could be attributed to the pressure generated by engaging the tool into the material, which induces plastic deformation in the subsurface layers. In fact, several research reports [37-40] have demonstrated that an increase in cutting parameters generates higher cutting forces (i.e. increases $E$ ), resulting in severe plastic deformation in the subsurface layers. A comparison between values obtained experimentally versus those predicted using the model is also presented in Figs. 7 and 8. Since all the experimental values are located within a $95 \%$ confidence interval, it can be concluded that the regression model fits the values observed very well.

\subsection{Modeling of cracked carbides evolution after machining}

A statistical model was obtained following the same procedure as described in section 3.1, to establish a correlation between $E, M R R$, and $A C C$. Statistics obtained for the best fitting curves are summarized in Table 5. A simultaneous increase in $E$ and $M R R$ results in increased ACC (see Figs. 9 and 10), which is in line with the conclusions drawn from Fig. 6.

In order to precisely determine the contribution of machining on the enhancement and evolution of the cracked carbides in the subsurface layer, the percentage of the cracked carbides in the as-received material was measured on polished surfaces and found to be $2.6 \%$. Therefore, this value was taken as the initial boundary condition for the modeling of the ACC evolution of as shown in Fig.9 and Fig.10. It can be seen on these figures that a square root function with the intercept point at $2.6 \%$ well describes the variation of $A C C$ with $E$ and $M R R$. The adjusted coefficients of correlation $R_{a d j}^{2}$ are 88.5 and $89.2 \%$ and the $P$-valueis 0 for both 
conditions, demonstrating a strong correlation between the model's inputs, $M R R$ and $E$, and output $A C C$.

Given that (i) $M R R \propto E$, (ii) $D L=f(\sqrt{M R R}, \sqrt{E})$ and (iii) $A C C=f(\sqrt{M R R}, \sqrt{E})$, it is expected that a relationship between $D L$ and $A C C$ exists, which is confirmed by Fig. 11.

\section{Validation of the proposed models}

The accuracy of the developed models was evaluated using two additional test conditions, as shown in Table 6. Validation tests were chosen from the study domain defined by the DOE. The values calculated by the models for both $D L$ thickness and $A C C$ were in good agreement with experimental ones. The maximum calculated relative error when using $\mathrm{E}$ as input was $3.6 \%$ for $D L$ and $-10 \%$ for $A C C$, the maximum relative calculated error determined using $M R R$ as input was $29 \%$ for the $D L$ and $-10 \%$ for $A C C$. The $29 \%$ error could be due to the super finishing condition used for validation of the proposed model. This condition leads to a material removal rate equal to $0.3 \mathrm{~cm} 3 / \mathrm{min}$ which is very close to the minimum $M R R$ used as input in the $D O E$ (i.e., $0.2 \mathrm{~cm} 3 / \mathrm{min}$ ). The close proximity between the measured and predicted values confirms the validity and good predictability of the proposed model. This is illustrated in Fig.12 where the variation of error level as a function of machining standardized position is presented. At the extreme of the range of study field, the error is much greater than the conditions in-between the extreme values. It is worth noting that, even with $28 \%$ error, the maximum calculated error (i.e. the difference between the calculated experimental and predicted values) is only $1.6 \mu \mathrm{m}$ for a predicted value of $D L$ equal to $4 \mu \mathrm{m}$. On the other hand, as shown in Table 6 , the validation condition number 13, which corresponds to testing conditions in the $D O E$ interval, the calculated error is $12 \%$ for DL corresponding to a $1 \mu \mathrm{m}$ difference between calculated and predicted values of $D L$. Therefore, it can be said that the errors calculated using the model are reasonable, and as a result, the response equations describing the microstructure alteration can be used to predict damage in the material using any combinations of cutting speed, feed rate, and depth of cut in the studied domain.

\section{Conclusions}

In this study, experimental results were used to develop models able to predict microstructural damages induced by hard turning of Inconel 718 located in the subsurface layer, especially the thickness of the deformed layer and the average of the cracked carbides, using response surface methodology. The following conclusions can be drawn from the study: 
- A strong correlation was identified between the thickness of the deformed layer and average of the cracked carbides.

- The evolution of the microstructure alteration as a function of material removal rate and deformation power can be well described by square root function.

- The thicknesses of the deformed layer and average of cracked carbides increase as material removal rate and deformation power increase.

- A higher feed rate and low cutting speed value leads to a higher deformed layer thickness and a higher percentage of cracked carbides.

\section{Acknowledgements}

The authors would like to acknowledge the National Science and Engineering Research Council NSERC, as well as Dr. Serafettin Engin and Dr. Elvi Dalgaard from Pratt \&Whitney Canada for their support. The first author also appreciates the efforts of Mrs. Jihane Ajaja and Dr. Hadi Ghasemi Nanesa in proofreading the manuscript. 


\section{References}

1. Kuo, C.M., et al., Aging effects on the microstructure and creep behavior of Inconel 718 superalloy. Materials Science and Engineering: A, 2009. 510-511: p. 289-294.

2. Thomas, A., et al., High temperature deformation of Inconel 718. Journal of Materials Processing Technology, 2006. 177(1-3): p. 469-472.

3. Ghosh, S., S. Yadav, and G. Das, Study of standard heat treatment on mechanical properties of Inconel 718 using ball indentation technique. Materials Letters, 2008. 62(17-18): p. 2619-2622.

4. Chamanfar, A., et al., Microstructural characteristics of forged and heat treated Inconel-718 disks. Materials \& Design, 2013. 52: p. 791-800.

5. Rao, G.A., et al., Effect of standard heat treatment on the microstructure and mechanical properties of hot isostatically pressed superalloy inconel 718. Materials Science and Engineering: A, 2003. 355(1-2): p. 114-125.

6. Fournier, D. and A. Pineau, Low cycle fatigue behavior of inconel 718 at $298 \mathrm{~K}$ and $823 \mathrm{~K}$. Metallurgical Transactions A, 1977. 8(7): p. 1095-1105.

7. Klocke, F., W. König, and K. Gerschwiler, Advanced Machining of Titanium- and Nickel-Based Alloys, in Advanced Manufacturing Systems and Technology, E. Kuljanic, Editor. 1996, Springer Vienna: Vienna. p. 7-21.

8. Ezugwu, E.O., J. Bonney, and Y. Yamane, An overview of the machinability of aeroengine alloys. Journal of Materials Processing Technology, 2003. 134(2): p. 233-253.

9. Ren, X. and Z. Liu, Influence of cutting parameters on work hardening behavior of surface layer during turning superalloy Inconel 718. The International Journal of Advanced Manufacturing Technology, 2016. 86(5): p. 23192327.

10. Zhou, J.M., V. Bushlya, and J.E. Stahl, An investigation of surface damage in the high speed turning of Inconel 718 with use of whisker reinforced ceramic tools. Journal of Materials Processing Technology, 2012. 212(2): p. 372 384.

11. Touazine, H., M. Jahazi, and P. Bocher, Accurate determination of damaged subsurface layers in machined Inconel 718. The International Journal of Advanced Manufacturing Technology, 2016: p. 1-9.

12. Ulutan, D. and T. Ozel, Machining induced surface integrity in titanium and nickel alloys: A review. International Journal of Machine Tools and Manufacture, 2011. 51(3): p. 250-280.

13. Kitagawa, T., A. Kubo, and K. Maekawa, Temperature and wear of cutting tools in high-speed machining of Inconel 718 and $\mathrm{Ti} \cdot 6 \mathrm{Al} \cdot 6 \mathrm{~V} \cdot 2 \mathrm{Sn}$. Wear, 1997. 202(2): p. 142-148.

14. Zhou, J.M., et al., Effects of Tool Wear on Subsurface Deformation of Nickel-based Superalloy. Procedia Engineering, 2011. 19: p. 407-413.

15. Huang, Q. and J.X. Ren, Surface integrity and its effects on the fatigue life of the nickel-based superalloy GH33A. International Journal of Fatigue, 1991. 13(4): p. 322-326.

16. Jeelani, S. and M.R. Collins, Effect of electric discharge machining on the fatigue life of Inconel 718 . International Journal of Fatigue, 1988. 10(2): p. 121-125.

17. Coelho, R.T., et al., Some effects of cutting edge preparation and geometric modifications when turning INCONEL $718^{\mathrm{TM}}$ at high cutting speeds. Journal of Materials Processing Technology, 2004. 148(1): p. 147-153.

18. Sharman, A.R.C., J.I. Hughes, and K. Ridgway, Workpiece Surface Integrity and Tool Life Issues When Turning Inconel 718 ${ }^{\mathrm{TM}}$ Nickel Based Superalloy. Machining Science and Technology, 2004. 8(3): p. 399-414.

19. Ozcelik, B., H. Oktem, and H. Kurtaran, Optimum surface roughness in end milling Inconel 718 by coupling neural network model and genetic algorithm. The International Journal of Advanced Manufacturing Technology, 2005. 27(3): p. 234-241.

20. Pawade, R.S. and S.S. Joshi, Multi-objective optimization of surface roughness and cutting forces in high-speed turning of Inconel 718 using Taguchi grey relational analysis (TGRA). The International Journal of Advanced Manufacturing Technology, 2011. 56(1): p. 47-62.

21. Amini, S., M.H. Fatemi, and R. Atefi, High Speed Turning of Inconel 718 Using Ceramic and Carbide Cutting Tools. Arabian Journal for Science and Engineering, 2014. 39(3): p. 2323-2330.

22. Tamang, S.K. and M. Chandrasekaran, Integrated optimization methodology for intelligent machining of inconel 825 and its shop-floor application. Journal of the Brazilian Society of Mechanical Sciences and Engineering, 2016: p. 1-13.

23. Provencher, P.R. and M. Balaziski, Automatic identification of feed marks in machined surface roughness profiles by correlating random variations. The International Journal of Advanced Manufacturing Technology, 2016. 82(5): p. $1305-1315$.

24. Ulutan, D., et al., Empirical Modeling of Residual Stress Profile in Machining Nickel-based Superalloys Using the Sinusoidal Decay Function. Procedia CIRP, 2014. 13: p. 365-370. 
25. Zhou, J., et al., Analysis of Subsurface Microstructure and Residual Stresses in Machined Inconel 718 with PCBN and Al2O3-SiCw Tools. Procedia CIRP, 2014. 13: p. 150-155.

26. Jafarian, F., H. Amirabadi, and M. Fattahi, Improving surface integrity in finish machining of Inconel 718 alloy using intelligent systems. The International Journal of Advanced Manufacturing Technology, 2014. 71(5): p. 817827.

27. Roquemore, K.G., Hybrid Designs for Quadratic Response Surfaces. Technometrics, 1976. 18(4): p. 419-423.

28. Rosadelima, L. and D.P. Lou, Some Small Response Surface Designs for Three-Factor Experiments in Int. Statistical Inst.: Proc. 58th World Statistical Congress. 2011: Dublin

29. Fang, J., Z. He, and L. Song, Evaluation of Response Surface Designs in Presence of Errors in Factor Levels. Communications in Statistics - Theory and Methods, 2015. 44(18): p. 3769-3781.

30. Liu, C., et al., Study on surface defects in milling Inconel 718 super alloy. Journal of Mechanical Science and Technology, 2015. 29(4): p. 1723-1730.

31. Pawade, R.S., et al., An investigation of cutting forces and surface damage in high-speed turning of Inconel 718. Journal of Materials Processing Technology, 2007. 192-193: p. 139-146.

32. Sadat, A.B. and J.A. Bailey, Some observations on surface damage during machining of a bearing bronze. Wear, 1986. 108(3): p. 255-268.

33. Zhou, J.M., et al., Identification of Subsurface Deformation in Machining of Inconel 718. Applied Mechanics and Materials, 2011. 117-119: p. 1681-1688.

34. Pawade, R.S., S.S. Joshi, and P.K. Brahmankar, Effect of machining parameters and cutting edge geometry on surface integrity of high-speed turned Inconel 718. International Journal of Machine Tools and Manufacture, 2008. 48(1): p. 15-28.

35. Chen, Y., et al., Investigations in subsurface damage when machining $\gamma^{\prime}$-strengthened nickel-based superalloy. Proceedings of the Institution of Mechanical Engineers, Part B: Journal of Engineering Manufacture, 2015.

36. Caruso, S., et al., Finite element modeling of microstructural changes in Waspaloy dry machining. The International Journal of Advanced Manufacturing Technology, 2016: p. 1-14.

37. Bartarya, G. and S.K. Choudhury, Effect of Cutting Parameters on Cutting Force and Surface Roughness During Finish Hard Turning AISI52100 Grade Steel. Procedia CIRP, 2012. 1: p. 651-656.

38. Rao, C.J., D.N. Rao, and P. Srihari, Influence of Cutting Parameters on Cutting Force and Surface Finish in Turning Operation. Procedia Engineering, 2013. 64: p. 1405-1415.

39. Rahman, M., W.K.H. Seah, and T.T. Teo, The machinability of inconel 718. Journal of Materials Processing Technology, 1997. 63(1): p. 199-204.

40. ÇOLAK, O., Investigation on Machining Performance of Inconel 718 in High Pressure Cooling Conditions. Journal of Mechanical Engineering, 2012. 58: p. 683-690. 


\section{List of Tables}

Table 1. Chemical composition of the investigated superalloy (wt.\%)

\begin{tabular}{lccccccccccc}
\hline Element & $\mathrm{Ni}$ & $\mathrm{Fe}$ & $\mathrm{Cr}$ & $\mathrm{Nb}$ & $\mathrm{Ti}$ & $\mathrm{Mo}$ & $\mathrm{V}$ & $\mathrm{Al}$ & $\mathrm{Ta}$ & $\mathrm{Si}$ & $\mathrm{C}$ \\
\hline wt.\% & 52.97 & 18.51 & 18.36 & 4.47 & 1.02 & 3.14 & 0.09 & 0.39 & 0.22 & 0.22 & 0.07 \\
\hline
\end{tabular}

Table 2. Assignment of levels to factors

\begin{tabular}{ccccccc}
\hline Factor & Unit & Level 1 & Level 2 & Level 3 & Level 4 & Level 5 \\
\hline$V_{c}$ & $\mathrm{~m} / \mathrm{min}$ & 33.0 & 49.0 & 58.0 & 67.0 & 83.0 \\
$f$ & $\mathrm{~mm} / \mathrm{rev}$ & 0.020 & 0.098 & 0.142 & 0.186 & 0.264 \\
$D o C$ & $\mathrm{~mm}$ & 0.179 & 0.230 & 0.265 & 0.300 & 0.351 \\
\hline
\end{tabular}

Table 3. Experimental results obtained using the Roquemore 311B hybrid design

\begin{tabular}{cccc|cc|ccc}
\hline \multicolumn{4}{c}{ Control factors } & \multicolumn{3}{c|}{ Calculated values } & \multicolumn{3}{c}{ Measured values } \\
\hline Run & $\begin{array}{c}V_{c} \\
{[\mathrm{~m} / \mathrm{min}]}\end{array}$ & $\begin{array}{c}f \\
{[\mathrm{~mm} / \mathrm{rev}]}\end{array}$ & $\begin{array}{c}D o C \\
{[\mathrm{~mm}]}\end{array}$ & $\begin{array}{c}M R R \\
{\left[\mathrm{~cm}^{3} / \mathrm{min}\right]}\end{array}$ & $\begin{array}{c}E \\
{[\mathrm{~W}]}\end{array}$ & $\begin{array}{c}F_{z} \\
{[\mathrm{~N}]}\end{array}$ & $\begin{array}{c}D L \\
{[\mu \mathrm{m}]}\end{array}$ & $\begin{array}{c}A C C \\
{[\%]}\end{array}$ \\
\hline 1 & 58 & 0.142 & 0.351 & 2.9 & 204 & 211 & 11.9 & 14.8 \\
2 & 58 & 0.142 & 0.179 & 1.5 & 120 & 124 & 11.3 & 12.9 \\
3 & 49 & 0.264 & 0.30 & 3.9 & 245 & 300 & 15.5 & 20.5 \\
4 & 58 & 0.142 & 0.265 & 2.2 & 163 & 168 & 10.0 & 16.0 \\
5 & 83 & 0.186 & 0.300 & 4.6 & 338 & 244 & 13.6 & 19.5 \\
6 & 67 & 0.020 & 0.300 & 0.4 & 80 & 71 & 7.2 & 9.9 \\
7 & 33 & 0.098 & 0.300 & 1.0 & 84 & 153 & 7.5 & 8.3 \\
8 & 58 & 0.142 & 0.265 & 2.2 & 161 & 167 & 9.0 & 14.0 \\
9 & 67 & 0.264 & 0.230 & 4.1 & 251 & 225 & 12.4 & 18.0 \\
10 & 83 & 0.098 & 0.230 & 1.9 & 169 & 122 & 8.5 & 14.3 \\
11 & 49 & 0.02 & 0.230 & 0.2 & 45 & 55 & 6.0 & 10.0 \\
12 & 33 & 0.186 & 0.230 & 1.4 & 102 & 186 & 8.0 & 14.3 \\
13 & 58 & 0.142 & 0.265 & 2.2 & 161 & 167 & 11.2 & 15.4 \\
\hline
\end{tabular}

Table 4: Estimated regression coefficients for $D L$

\begin{tabular}{lcccc}
\hline \multicolumn{1}{c}{ Curve fitting } & $\mathrm{R}^{2}(\%)$ & $\left.\mathrm{R}_{\text {adj }}^{2} \%\right)$ & P-value & \multicolumn{1}{c}{ Model equation } \\
\hline$D L=a \sqrt{M R R}$ & 97.5 & 97.5 & 0 & $D L=7.06 \sqrt{M R R}$ \\
$D L=a \sqrt{E}$ & 89.3 & 89.3 & 0 & $D L=0.82 \sqrt{E}$ \\
\hline
\end{tabular}

Table 5: Estimated regression coefficients for $A C C$

\begin{tabular}{ccccc}
\hline Curve fitting model & $\mathrm{R}^{2}(\%)$ & $\left.\mathrm{R}_{\text {adj }}^{2} \%\right)$ & $\mathrm{P}$ value & Equation constants \\
\hline$A C C=a \sqrt{M R R}+b$ & 90.2 & 89.2 & 0 & $A C C=7.37 \sqrt{M R R}+4.02$
\end{tabular}


Table 6: Validation of the proposed models by two tests

\begin{tabular}{ccccccccccccc}
\hline Test & $\begin{array}{c}V C \\
{[\mathrm{~m} / \mathrm{min}]}\end{array}$ & $\begin{array}{c}f \\
{[\mathrm{~mm} / \mathrm{rev}]}\end{array}$ & $\begin{array}{c}a p \\
{[\mathrm{~mm}]}\end{array}$ & $\begin{array}{c}F z \\
{[\mathrm{~N}]}\end{array}$ & $\begin{array}{c}M R R \\
{\left[\mathrm{~cm}^{3} / \mathrm{min}\right]}\end{array}$ & $\begin{array}{c}E \\
{[\mathrm{~W}]}\end{array}$ & $\begin{array}{c}D L \\
\text { exp } \\
{[\mu \mathrm{m}]}\end{array}$ & $\begin{array}{c}\text { DL } \\
\text { pred } \\
{[\mu \mathrm{m}]}\end{array}$ & $\begin{array}{c}\text { DL } \\
\text { error } \\
{[\%]}\end{array}$ & $\begin{array}{c}A C C \\
\text { exp } \\
{[\%]}\end{array}$ & $\begin{array}{c}A C C \\
\text { pred } \\
{[\%]}\end{array}$ & $\begin{array}{c}A C C \\
\text { error } \\
{[\%]}\end{array}$ \\
\hline 13 & 55 & 0.0762 & 0.254 & 110 & 1.1 & $\mathbf{1 0 1}$ & 8.3 & 8.2 & 1 & 10.9 & 12.0 & -10 \\
14 & 49 & 0.0508 & 0.127 & 54 & 0.3 & $\mathbf{4 4}$ & 5.6 & 5.4 & 4 & 8.9 & 8.6 & 3 \\
13 & 55 & 0.0762 & 0.254 & 110 & $\mathbf{1 . 1}$ & 101 & 8.3 & 7.3 & 12 & 10.9 & 12.0 & -10 \\
14 & 49 & 0.0508 & 0.127 & 54 & $\mathbf{0 . 3}$ & 44 & 5.6 & 4.0 & 29 & 8.9 & 8.9 & 0 \\
\hline
\end{tabular}




\section{List of Figures}

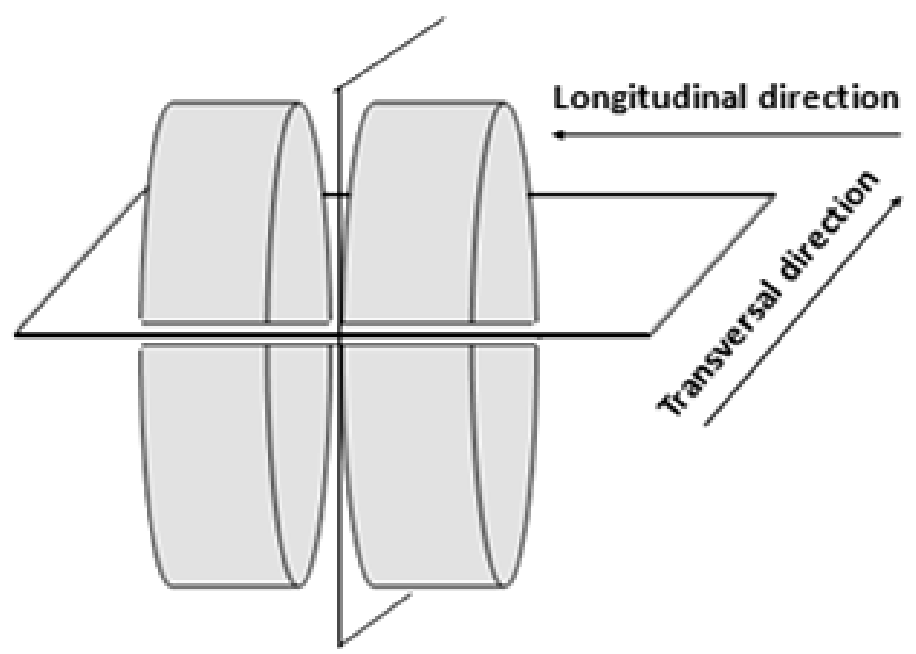

Fig.1

Fig. 1: Schematic of sample cutting procedure in transversal and longitudinal directions

\section{Machined surface}

\section{Nickel coating}

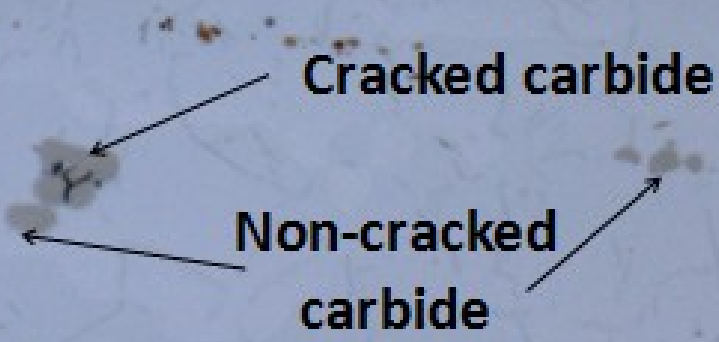

\section{$20 \mu \mathrm{m}$}

Fig.2: Machined subsurface showing carbide cracking 


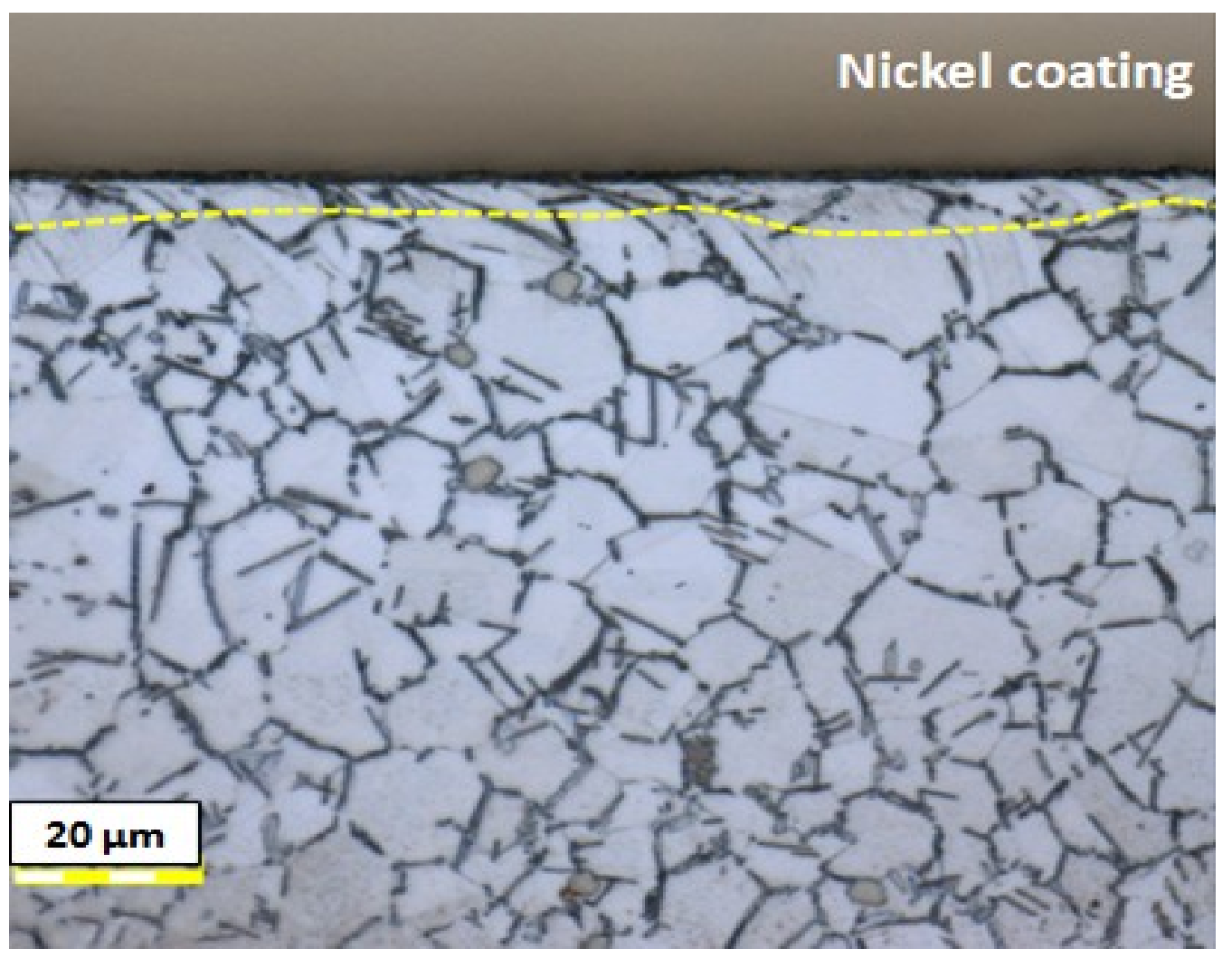

Fig. 3: Deformed grain boundaries near the machined surface 


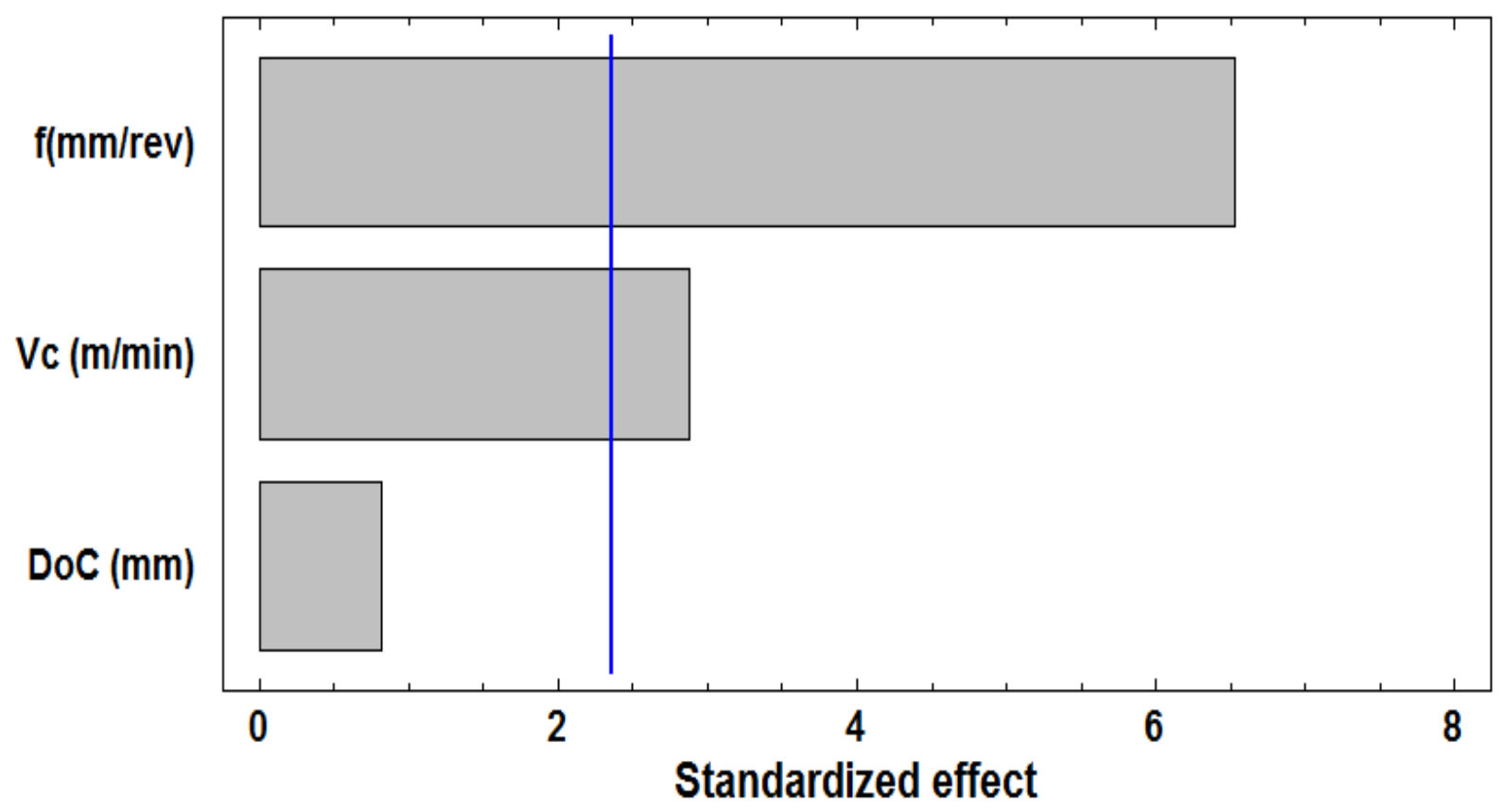

Fig. 4: Pareto diagram of $A C C$

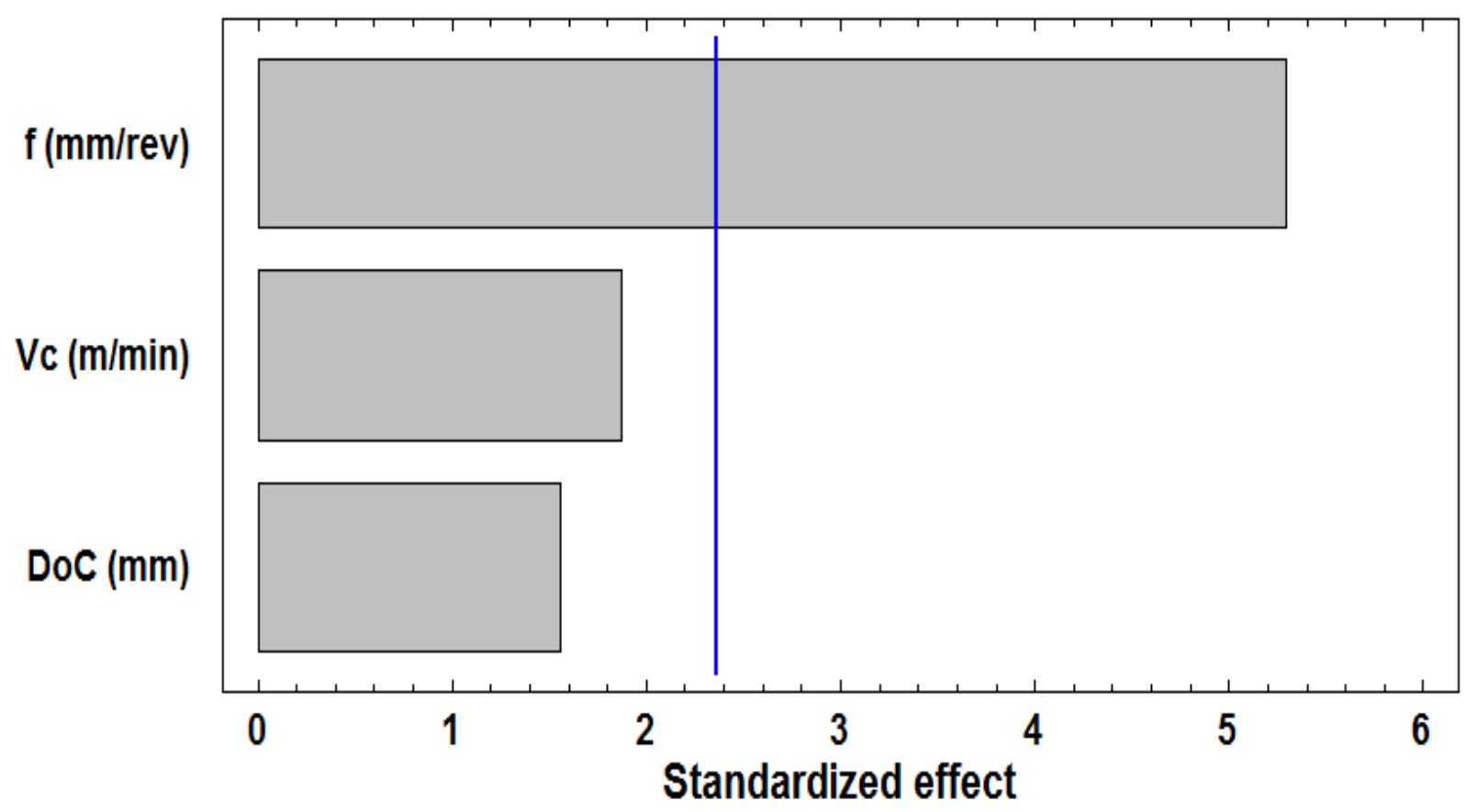

Fig. 5: Pareto diagram of $D L$ 


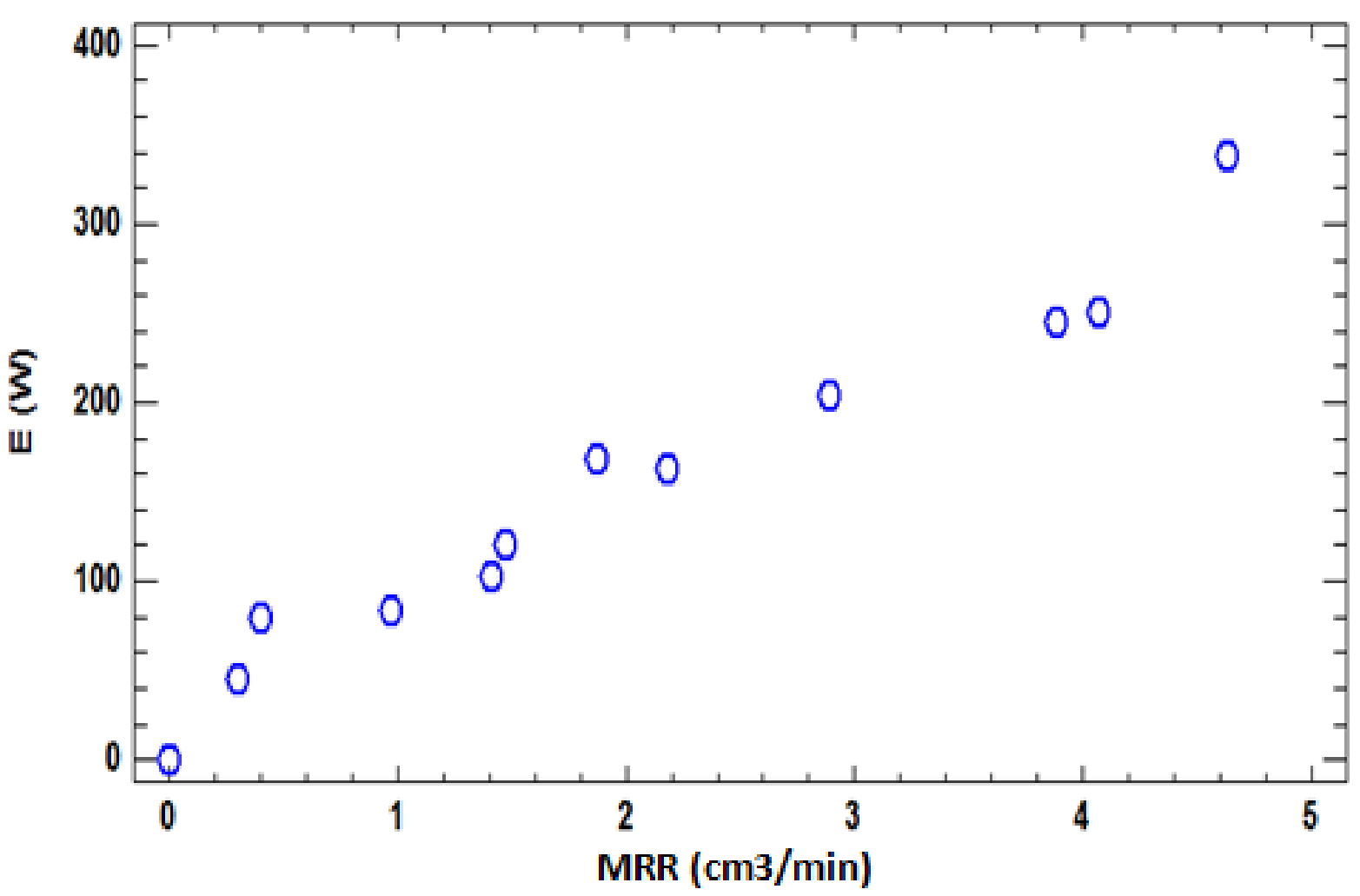

Fig. 6: Evolution of $\mathrm{E}$ as a function of MRR

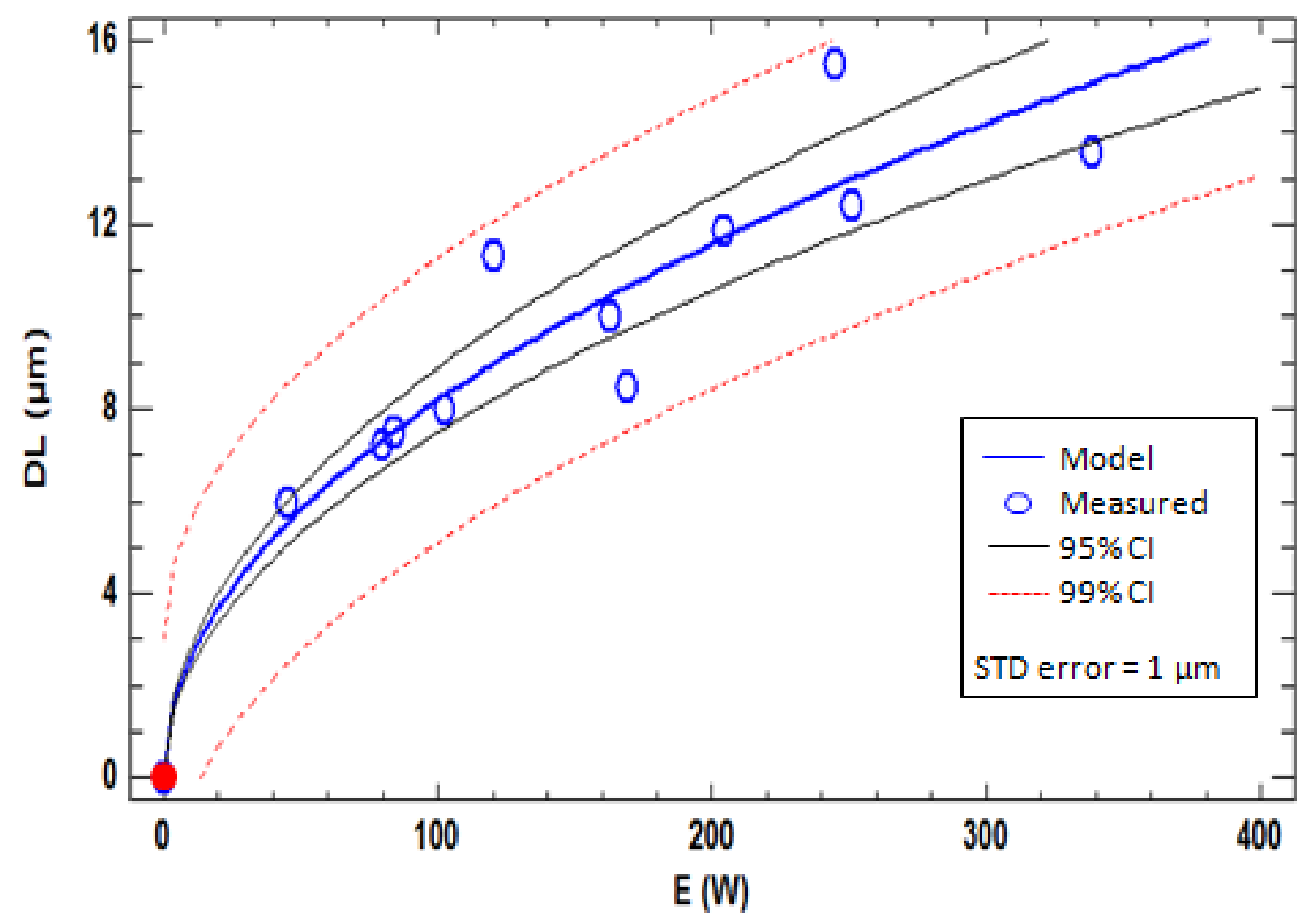

Fig. 7: Evolution of DL as a function of $E$ 


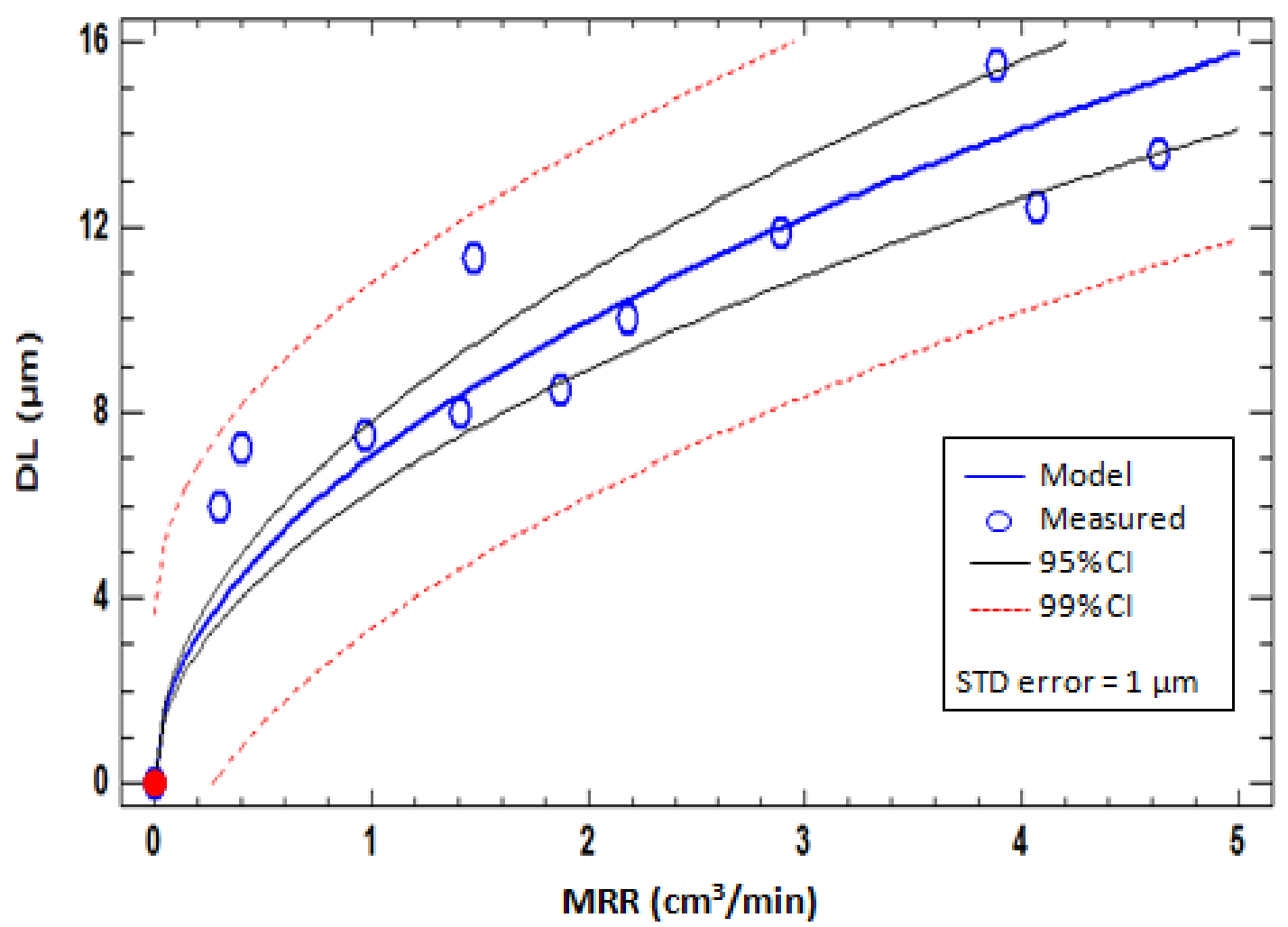

Fig. 8: Evolution of DL as a function of MRR

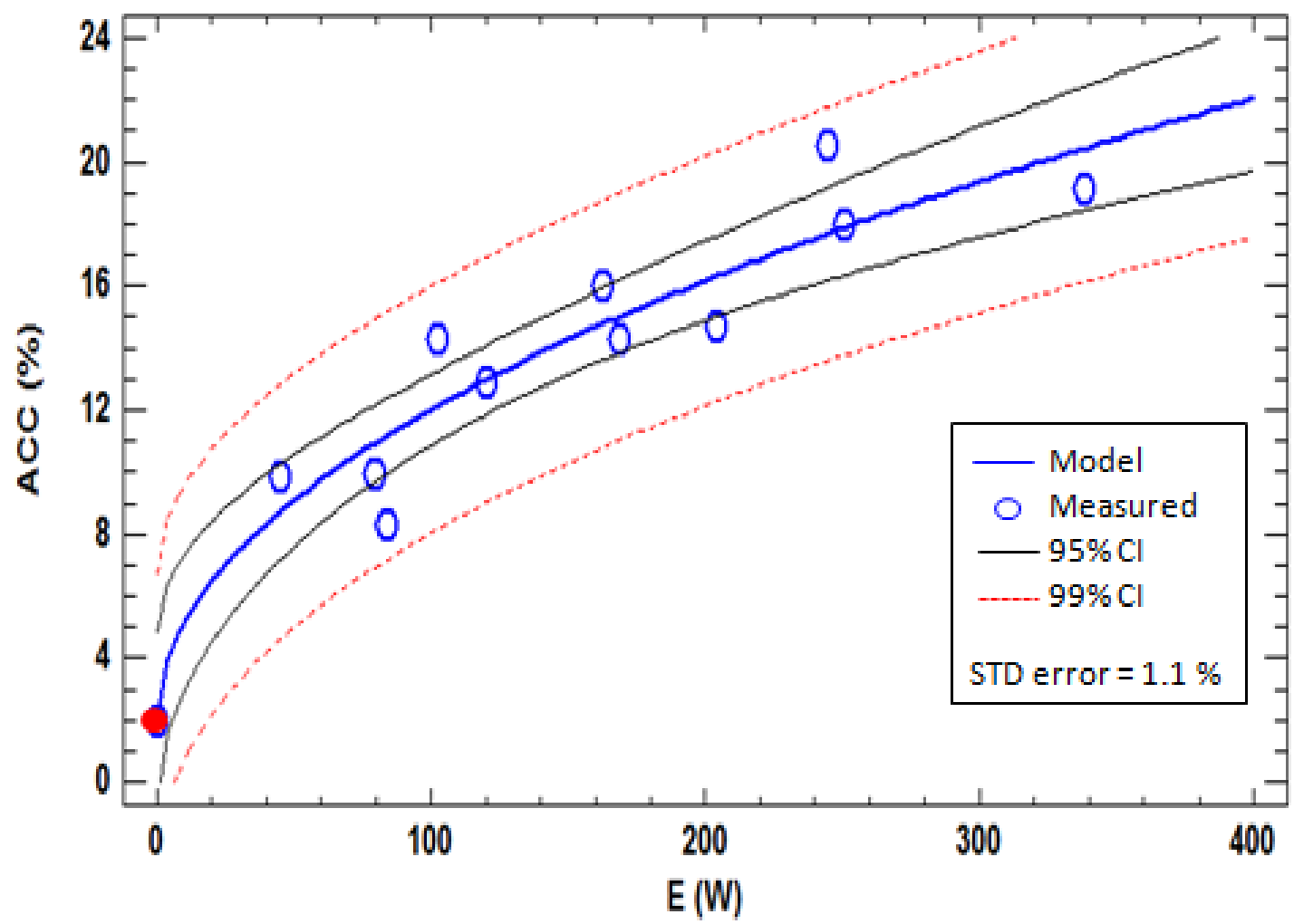

Fig. 9: Evolution of ACC as a function of $E$ 


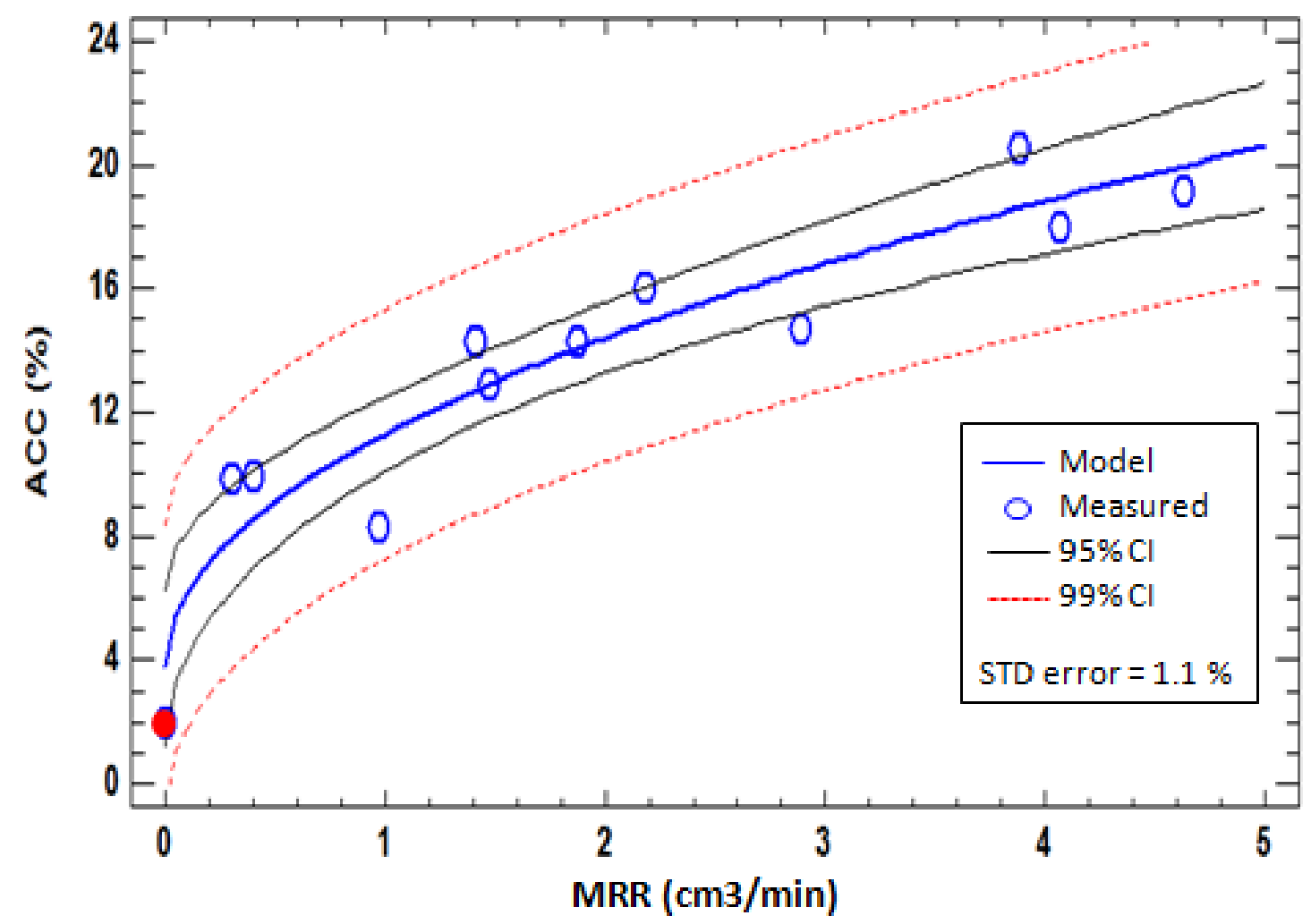

Fig. 10: Evolution ACC as a function of MRR

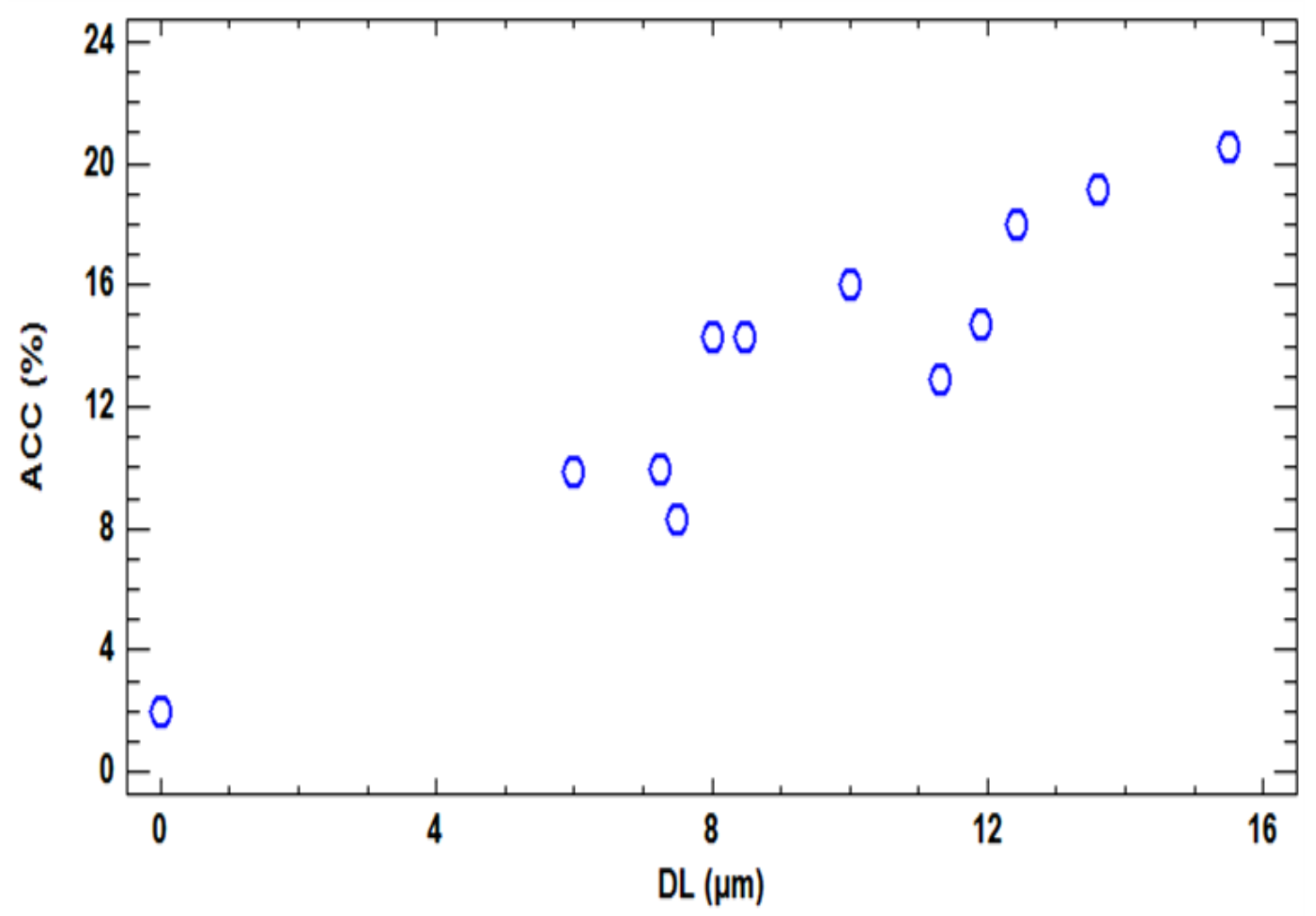

Fig. 11: Evolution of percents ACC as a function of DL thickness 


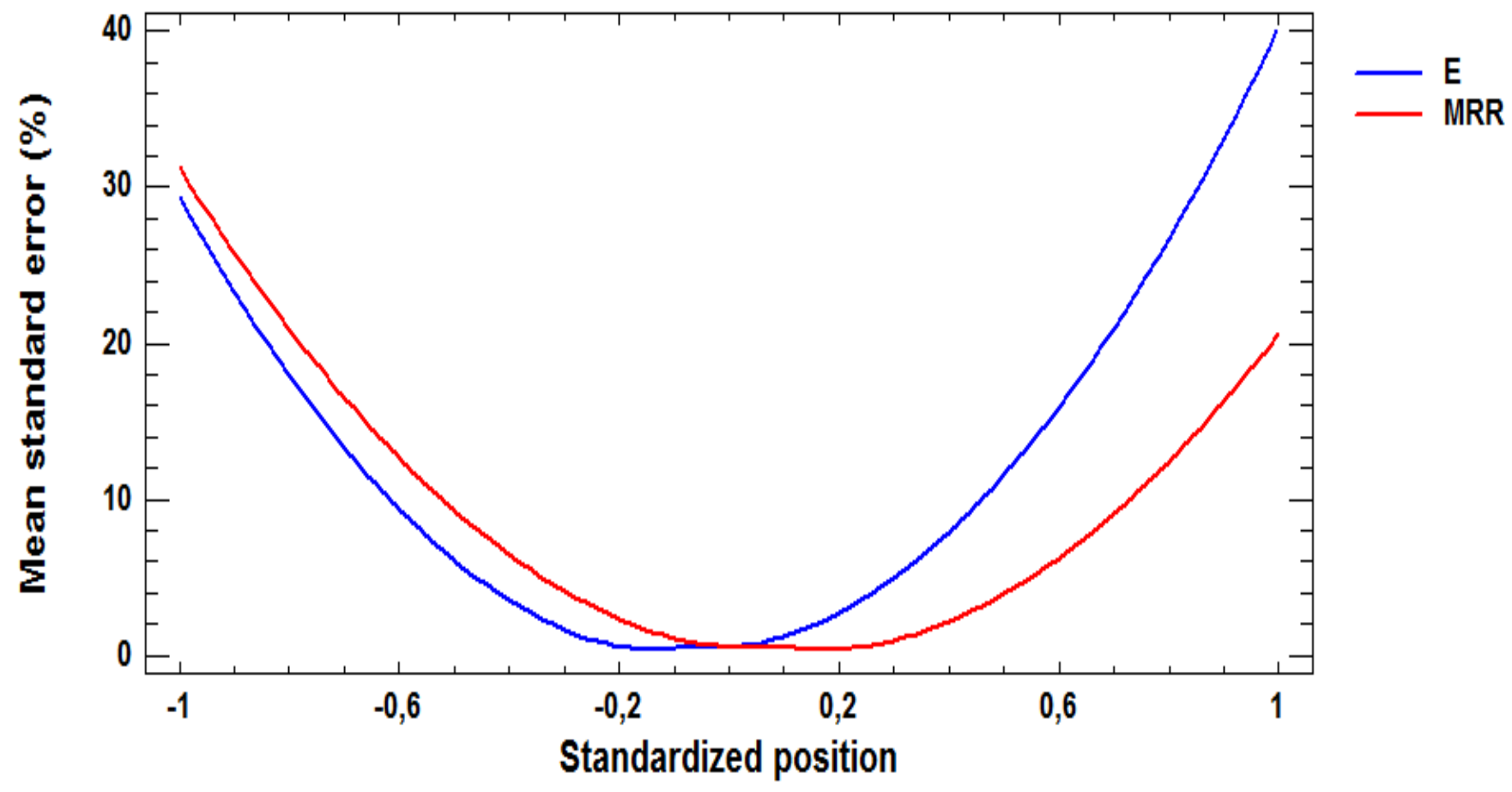

Fig. 12: Prediction profile of the mean error as a function of the standardized position 